\title{
Assessing Water Resistance and Surface Properties of ETICS
}

\section{Giovanni Borsoi ${ }^{1}$, João Luís Parracha ${ }^{2}$, Pedro Caiado ${ }^{1}$, Inês Flores-Colen ${ }^{1}$, Amélia Dionísio $^{3}$ and Rosário Veiga ${ }^{2}$}

${ }^{1}$ CERIS, Civil Engineering Research and Innovation for Sustainability, Instituto Superior Técnico, University of Lisbon, 1049-001, Lisbon, Portugal, giovanni.borsoi@tecnico.ulisboa.pt, ines.flores.colen@tecnico.ulisboa.pt, pedrocpcaiado@gmail.com

${ }^{2}$ LNEC, National Laboratory for Civil Engineering, Av. do Brasil 101, Lisbon, Portugal, jparracha@1nec.pt, rveiga@lnec.pt

${ }^{3}$ CERENA, Centro de Recursos Naturais e Ambiente, Instituto Superior Técnico, University of Lisbon, 1049-001, Lisbon, Portugal, amelia.dionisio@tecnico.ulisboa.pt

\begin{abstract}
External Thermal Insulation Composite Systems (ETICS) contribute significantly to building energy efficiency by increasing thermal insulation, correcting thermal bridges and reducing interior water condensation. Additionally, these solutions protect the structure and thus enhance the durability of the building. The use of ETICS remarkably increased in the last three decades also due to the introduction of new international and national regulations on building energy efficiency (e.g. EU Directive on the Energy Performance of Buildings). ETICS are constantly exposed to weathering (e.g. wind, rain, sun light) and anthropic factors (e.g. graffiti, environmental pollutants), which can lead to cracks, biocolonization and stains and thus affect ETICS durability. However, international technical documents on the evaluation of the effectiveness and durability of ETICS do not consider the possible synergies between these factors, which can trigger and speed up multiple biological, mechanical and chemical degradation processes. With the aim of filling this gap, this paper focused on the water resistance and surface properties of several ETICS surface coatings, verifying possible connections between these factors. The moisture transport properties (capillary water absorption, water vapour permeability, and drying kinetics) and surface properties (colour, brightness and roughness) of some commercially available ETICS were tested. This study is part of a wider research project (WGB_Shield: resistance for water, graffiti and biocolonization of external thermal insulation systems) that aims at the development of ETICS with improved durability in urban environment.
\end{abstract}

Keywords: ETICS, Durability, Water Behaviour, Surface Properties.

\section{Introduction}

The implementation of long-term building renovation strategies is a key challenge in modern society. As a matter of fact, $40 \%$ of energy in $\mathrm{EU}$ is used for buildings (producing $36 \%$ of total $\mathrm{CO}_{2}$ emission) and $2 / 3$ of this energy consumption is used for heating and cooling. For these reasons, EU has set new rules also for energy efficiency, both in new and retrofitted buildings, with the objective of achieving a nearly zero energy built environment by 2050 (EPBD 2010).

In this context, External Thermal Insulation Composite Systems (ETICS), sometimes also identified as External Wall Insulation (EWI, in UK) or Exterior insulation finishing system (EIFS, in the US), can significantly improve the thermal performance and energetic efficiency of buildings. In fact, these systems can improve thermal insulation, reduce thermal bridges and avoid water 
condensation within masonry. Additionally, these systems can increase occupants' health and wellbeing, by improved air quality, and thermal comfort (Barreira and P. de Freitas, 2013).

Hence, ETICS have been established in the last three decades among the most used solution to improve the energy efficiency of buildings, with a wide variety of system configurations and design. It is estimated that more than 2 billion $\mathrm{m}^{2}$ have already been installed in Europe (Pasker, 2017).

These systems are generally composed of a variety of materials, which include insulation materials (Schiavoni et al., 2016), basecoats with mineral binders (e.g. air or hydraulic lime, cement), finishing coatings (e.g. silicate, acrylates, siloxanes and additives (e.g. aggregates, pigments, biocides). The compatibility among these components is a crucial factor to achieve an efficient and durable system.

According to the European Technical Approval Guideline (ETAG 004), which gather the technical approval requirements of ETICS in the EU zone, service life of ETICS should be over 25 years. It is thus necessary to plan a careful maintenance of these systems.

As a matter of fact, ETICS are constantly exposed to weathering agents (e.g. wind, rain, sun light, etc.) as well as to direct (e.g. vandalism) and indirect (e.g. environmental pollutants) anthropic factors. These factors have often a synergic effect on the affected surface, triggering and speeding up multiple biological, mechanical and chemical degradation processes.

Degradation patterns are typically identified in the alteration of the physical-chemical, aesthetical and mechanical properties of ETICS, with formation of e.g. cracks and stains,

In this paper, the moisture transport properties (water capillary absorption, drying kinetics, water vapour permeability) and superficial properties (colour, brightness, surface roughness) of several commercially available ETICS were studied. The main aim was the identification of the possible connection between these properties and, ultimately, a deeper comprehension of the dynamics behind

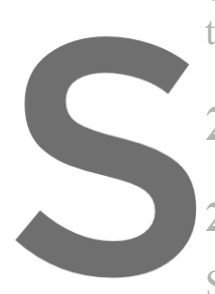
the durability of ETICS

\section{Materials and}

2.1 Materials
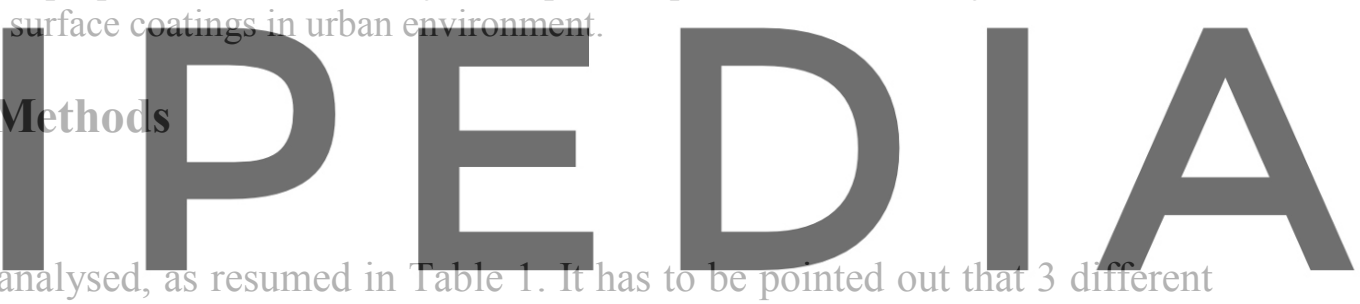

ETICS producers were considered (systems 1 to 3 ; systems 4 to 8 ; systems 9 to

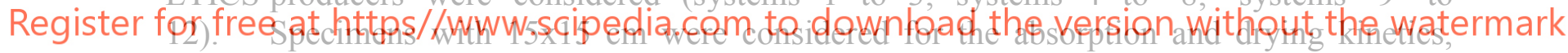

whereas cylindrical specimens ( $8 \mathrm{~cm}$ diameter) were used for the water vapour permeability

test. Specimens $5 \times 5 \mathrm{~cm}$ were used for the evaluation of the surface properties (colour, brightness, roughness). The specimens have thickness varying between 3.9 and $6.5 \mathrm{~cm}$.

\subsection{Methods}

\subsubsection{Absorption and drying kinetics}

Capillary absorption tests were performed according to ETAG 004 (EOTA, 2013) in a conditioned room (at $\mathrm{T}=23 \pm 2^{\circ} \mathrm{C}$ and $65 \pm 5 \% \mathrm{RH}$ ). A total of four cycles (with measurements at $3 \mathrm{~min}, 1 \mathrm{~h}, 4 \mathrm{~h}, 8 \mathrm{~h}$ and $24 \mathrm{~h}$ ) of capillary absorption were conducted. Capillary water absorption coefficient was obtained by the slope of the initial phase of the curve that expresses the water absorption as a function of the square root of time. 
Giovanni Borsoi, João Luís Parracha, Pedro Caiado, Inês Flores-Colen, Amélia Dionísio and Rosário Veiga

Table 1. ETICS identification and composition (EPS = Expanded polystyrene; ICB: Insulation cork Board; $\mathrm{MW}=$ Mineral wool).

\begin{tabular}{|c|c|c|c|}
\hline Systems & $\begin{array}{c}\text { Thermal } \\
\text { Insulation }\end{array}$ & Base Coat & Finishing coat \\
\hline 1 & EPS & $\begin{array}{l}2 \text { layers of cement- } \\
\text { based mortar }+ \text { mesh }\end{array}$ & $\begin{array}{l}\text { Primary: water-based dispersions of acrylic co-polymer } \\
\text { Finishing: acrylic paint + quartz aggregate }\end{array}$ \\
\hline 2 & EPS & \multirow[t]{2}{*}{$\begin{array}{l}\text { Cement-based mortar }+ \\
\text { mesh }\end{array}$} & $\begin{array}{l}\text { Primary: water-based acrylic dispersion } \\
\text { Finishing: a) water-based acrylic co-polymer }+ \text { pigment }+ \text { marble } \\
\text { powder } \\
\text { b) water-based acrylic paint } \\
\text { Primary: water-based acrylic dispersion }\end{array}$ \\
\hline 3 & EPS & & $\begin{array}{c}\text { Finishing: water-based acrylic co-polymer + pigment + marble } \\
\text { powder }\end{array}$ \\
\hline 4 & ICB & \multirow{2}{*}{$\begin{array}{l}\text { Hydraulic lime and } \\
\text { cement mortar + mesh }\end{array}$} & Mortar: air lime + hydraulic binder + organic additives \\
\hline 5 & ICB & & Primary: acrylic co-polymer + mineral additives \\
\hline 6 & EPS & \multirow[b]{2}{*}{$\begin{array}{l}\text { Cement-based mortar } \\
+ \text { - mesh }\end{array}$} & Finishing: acrylic paint + mineral aggregate + pigments \\
\hline 7 & MPS & & $\begin{array}{l}\text { Primary: acrylic co-polymer }+ \text { mineral aggregate } \\
\text { Finishing: acrylic paint }+ \text { organic additives }+ \text { pigments } \\
\text { Primary: acrylic co-polymer }+ \text { mineral aggregate } \\
\text { Finishing: acrylic paint }+ \text { mineral aggregate }+ \text { pigments }\end{array}$ \\
\hline & ICB & \multirow{2}{*}{$\begin{array}{l}\text { Hydraulic lime and } \\
\text { cork aggregate mortar } \\
+ \text { mesh }\end{array}$} & $\begin{array}{l}\text { Primary: water-based dispersions of silicate } \\
\text { Finishing: water-based silicate paint }+ \text { organic additives }+ \text { pigments }\end{array}$ \\
\hline 10 & $\mathrm{ICB}$ & & \multirow[b]{2}{*}{$\begin{array}{l}\text { Primary: acrylic dispersion }+ \text { mineral aggregate } \\
\text { Finishing: acrylic paint }+ \text { siloxane resin + marble powder }\end{array}$} \\
\hline 11 & $\begin{array}{l}\text { EPS } \\
\text { MW }\end{array}$ & $\begin{array}{l}\text { Hydraulic lime and } \\
\text { cenent moftar + mesh }\end{array}$ & \\
\hline
\end{tabular}

variation of mass was constant for all specimens. Two drying phases were determined: DR1 -

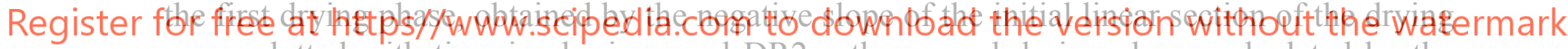
curve plotted with time in abscissa; and DR2 - the second drying phase, calculated by the negative slope of the linear section of the drying curve, plotted against the square root of time in abscissa. Drying index (DI) was obtained by Equation (1), in which $M_{x}$ is the mass of the specimen registered during the drying process $(\mathrm{g}), M_{l}$ is the mass of the specimen in a dry state $(\mathrm{g}), M_{3}$ is the mass of the specimen in a saturated state (this mass corresponds to the mass at the beginning of the drying process $\left(t_{0}\right), t_{f}$ is the time at the end of the drying process.

$$
D I=\frac{\int_{t_{0}}^{f} f\left(\frac{M_{x}-M_{I}}{M_{l}}\right) d t}{\left(\frac{M_{3}-M_{I}}{M_{I}}\right) \times t_{f}}
$$

\subsubsection{Water vapour permeability}

Water vapour permeability (WVP) tests were performed according to ETAG 004 (EOTA, 2013), adopting the dry cup method, i.e. sealing the lateral and bottom side of ETICS specimens within a recipient which contains a dryer substance $\left(\mathrm{CaCl}_{2}\right)$ than the external 
conditions. The lateral sides are sealed with paraffin, whereas the superficial finishing of the ETICS is exposed to the external environment. The cup is filled with a dessicant $\left(\mathrm{CaCl}_{2}\right)$, which keeps the relative humidity $(\mathrm{RH})$ inside the cup fixed at $\approx 20 \%$. All specimens are then stored within a climatic chamber at $\mathrm{T}=23 \pm 2^{\circ} \mathrm{C}$ and $50 \pm 5 \% \mathrm{RH}$. Hence, water vapour is forced from the external environment $(50 \% \mathrm{RH})$ to the interior of the cup $(\approx 20 \% \mathrm{RH})$, fluxing through the layers of the ETICS. Specimens were weighted over time, till stabilization of the specimens' weights. The change in the mass of the cup's content is used to quantify the water vapour permeability of the ETICS.

Based on the obtained results, the following parameters can be obtained by using the following equations:

$$
\begin{aligned}
\Lambda & =\frac{m}{A \times \Delta_{p}} \\
\mu & =\frac{1.94 \times 10^{-10}}{\Lambda \times e} \\
S_{d} & =\mu \times e
\end{aligned}
$$

where $\Lambda$ is the water vapour permeance $\left(\mathrm{kg} / \mathrm{m}^{2}\right.$.s.Pa), which defines the Wvp; $m$ is the slope of the linear relation between mass variation and time $(\mathrm{kg} / \mathrm{s}), A$ the specimen area, $\Delta p$ is the vapour pressure difference between the exterior and interior $(\mathrm{Pa})$, referred to the thickness of the specimen ( $m$ ), $\mu$ the water vapour diffusion resistance factor, $S d$ the diffusion-equivalent air-layer thickness $(\mathrm{m})$ Furthermore, the thermal separately, in order to WVP of the complete equivalent air-layer thickness $(S$.
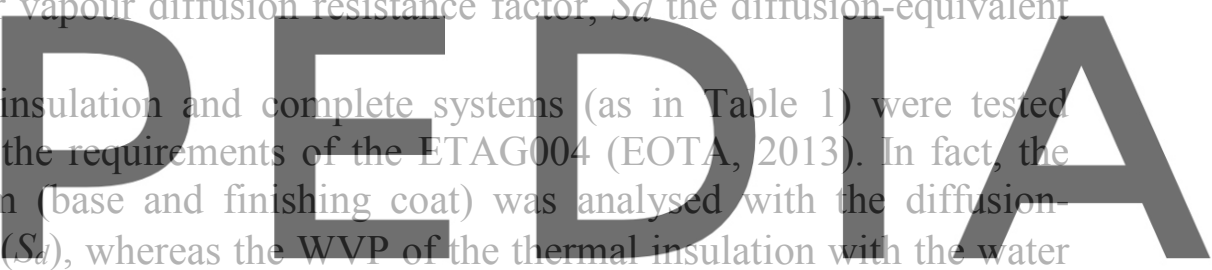

vapour diffusion resistance factor $(\mu)$.

Register for free at https//www.scipedia.com to download the version without the watermark

\subsubsection{Colour and brightness}

Colour was assessed with a colorimeter Minolta CR-410 Chroma Meter, by measuring the three colour coordinates $\left(L^{*}, a^{*}, b^{*}\right)$ of the CieLAB colour system. $L^{*}$ is the the lightness, which varies from 0 (black) to 100 (white), whereas $a^{*}$ and $b^{*}$ identify the colour, i.e. the chromatic coordinates of red-greed $\left(+a^{*}\right.$ refers to red, $-a^{*}$ to green) and yellow-blue $\left(\left(+b^{*}\right.\right.$ refers to yellow, $-b^{*}$ to blue). The chroma or colour saturation is calculated based on the values of $a^{*}$ and $b^{*}$ :

$$
C=\sqrt{a^{2}+b^{2}}
$$

The total colour difference $\left(\Delta E^{*}\right)$, which takes into account the differences between the $\mathrm{L}$, $\mathrm{a}, \mathrm{b}$ of the specimens and a standard/reference specimen, can be calculated as follows:

$$
\Delta E^{*}=\sqrt{\Delta L^{* 2}+\Delta a^{* 2}+\Delta b^{* 2}}
$$

Each specimen was analysed in 4 different spots, using a standard illuminant D65 (which 
corresponds to average daylight, including Uv wavelength region, with a correlated colour temperature of $6504 \mathrm{~K}$ ). The colorimeter was set to measure 3 repeated times in each spot. The relative average values and standard deviations were considered.

Brightness test was performed according to ASTM D6578 (ASTM, 1987). A Rhopoint Novo- Gloss Lite equipment was used, measuring the brightness with a light source angle of $60^{\circ}$ (suitable for matte specimens). The brightness (Gloss Unit - GU) was tested in 9 different spots in each specimen, considering the average value and relative standard deviation.

\subsubsection{Surface roughness}

An Elcometer 223digital surface profile gauge was used to measure the peak-to-valley height (surface roughness) of the specimens. This equipment can measure up to $2 \mathrm{~mm}$, with a resolution of $0,001 \mathrm{~mm}$. Surface roughness was tested in 9 different spots in each specimen, considering the average value and relative standard deviation.

\section{Results and Discussion}

\subsection{Capillary Absorption and Drying Tests}

Results obtained for capillary absorption and drying kinetics are presented in Figure 1 and Table 2. It can be observed that the systems 4 and 5, from the same producers and both with ICB, have the higher capillary absorption values at $1 \mathrm{~h}$, as well as the higher capillarity coefficient (Table 2). However, those values are $<1 \mathrm{~kg} / \mathrm{m}^{2}$, thus meeting the requirements ETAG 004 for the technical approval of ETCS. Systems cement-based base coat, present the higher capillary absorption $\left.1.46 \mathrm{~kg} / \mathrm{m}^{2}\right)$. On the other hand, system 2 have the slower $\mathrm{kg} / \mathrm{m}^{2}$ ). This latter system, sinnilarly to system.

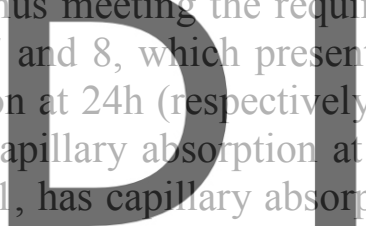

$\mathrm{kg} / \mathrm{m}^{2}$, and, thus, according to ETAG 004, those systems are resistant to freeze-thaw cycles. It

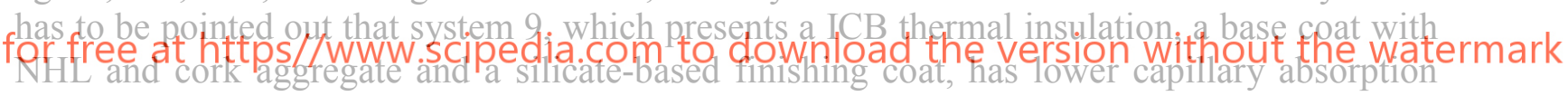
values, when compared to system 10, which differs only for its acrylic-based finishing coat. This confirms that this silicate-based finishing coat has lower capillary absorption, when compared to the referred acrylic-based finishing coat.

Additionally, if comparing systems 2 and 3, which have the same base coat, it can be concluded that the combination of an acrylic-based and co-polymeric acrylic finishing coat (system 2) plays an important role in the reduction of the water absorption, which is considerably lower (44\%) compared to system 3, which has only one layer of finishing coat.

Finally, it can be observed a significant difference between the capillary coefficient of systems 6 and 8, which differ only for their thermal insulation material (EPS and MW, respectively), as well as for systems 11 and 12, which again differ only for their thermal insulation materials (EPS and MW).

This can indicate that liquid water reaches the insulation layer and that there is an influence of the thermal insulation material on the capillary absorption, i.e. a higher and faster absorption of MW, when compared to EPS.

When observing drying kinetics, it can be noted that system 7 has the highest DR1 (which corresponds to water transport in the liquid phase), DR2 (which corresponds to water vapour 
(a)

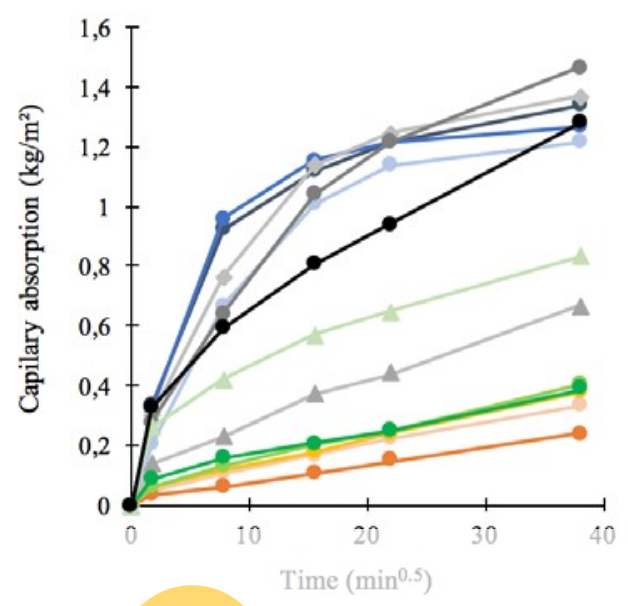

(b)

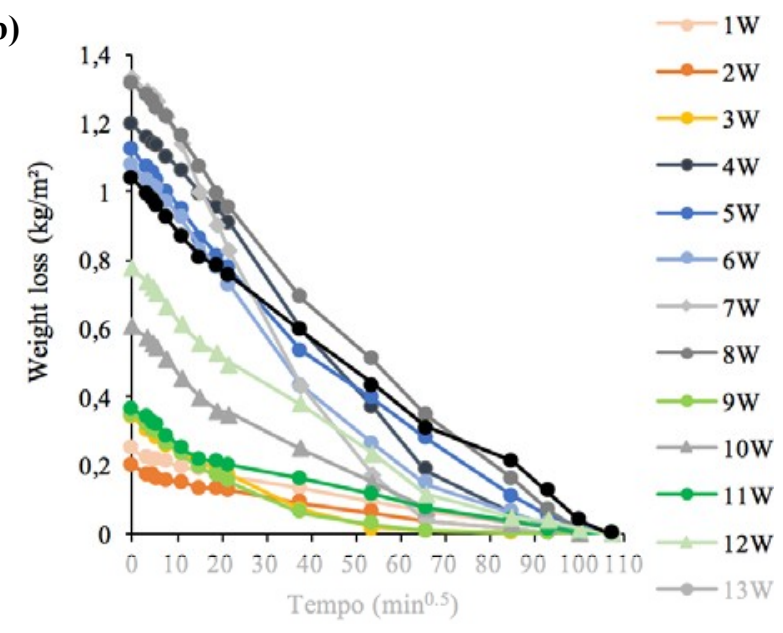

Figure 1. Capillary absorption (a) and drying curves (b) of the ETICS specimens.

diffusion) and drying index (0.94). Similar trends were observed for systems 4, 5, 6 and 8 (all from the same producers), which are also the systems with higher capillary absorption values. Conversely, ETICS 1, 2, 3 and 11 have the highest DR1 and DR2. It can be concluded that, generally, the system that absorbed more water by canillarity, are those with faster drying, which allows for some compensation and a possible adequate global behaviour.

3.2 Water Vapour Permealbility Results are presented in Table 2. The highest values of water vapour diffusion resistance
were registered for ETICS 1 (65.75) and 2 (65.22), followed by systems and 11 (48.94) and 3

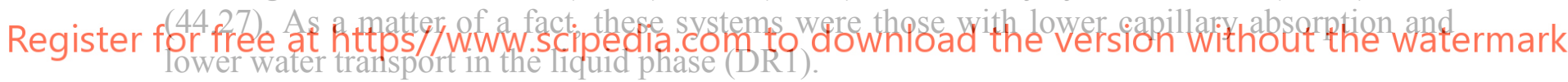

Conversely, systems 4, 5 and 8, those with higher capillary absorption, present lower values of water vapour diffusion resistance, with higher WVP and thus faster drying. A different trend was observed for systems 6 and 7, which have both a higher water vapour diffusion resistance and water absorption when compared to ETICS 8. This behaviour can hinder a suitable drying of this system.

However, when verifying the diffusion-equivalent air-layer thickness of the base and finishing coat of the systems (by subtracting the $S_{d}$ of the whole system to that of the thermal insulation), these values are $<2 \mathrm{~m}$ in all cases. Thus, all systems are in agreement with the requirements of the ETAG 004, which define $\mathrm{S}_{\mathrm{d}}$ values limits of $2 \mathrm{~m}$ for EPS systems (specimens 1,2,3,6,7,11) and 1m for MW systems (specimens 8,12).

\subsection{Colour and Brightness}

Results presented in Figure 2 indicate a low chroma for all systems (minimum $L^{*}$ at 71.71 , for ETICS 5), with shades of grey and a tendency to yellow (positive $b^{*}$ values). More specifically, systems 8 and 12, those with MW thermal insulation, have the higher $b^{*}$ values. In all systems, the $\mathrm{a}^{*}$ values are close to zero, i.e. to an ideal white colour. 
Giovanni Borsoi, João Luís Parracha, Pedro Caiado, Inês Flores-Colen, Amélia Dionísio and Rosário Veiga

Table 2. Capillary water absorption, drying and water vapour permeability test results.

\begin{tabular}{|c|c|c|c|c|c|c|c|c|}
\hline \multirow[b]{2}{*}{ Systems } & \multicolumn{2}{|c|}{ Capillary absorption } & \multicolumn{3}{|c|}{ Drying } & \multicolumn{3}{|c|}{ WVP } \\
\hline & $\begin{array}{l}\text { Capillary } \\
\text { absorption } \\
1 \mathrm{~h}\left(\mathrm{~kg} / \mathrm{m}^{2}\right)\end{array}$ & $\begin{array}{c}\mathrm{Cc} \\
\left(\mathrm{kg} / \mathrm{m}^{2} \cdot \mathrm{min}^{0.5}\right)\end{array}$ & $\begin{array}{c}\text { DR1 } \\
\left(\mathrm{kg} / \mathrm{m}^{2} \cdot \min ^{0.5}\right)\end{array}$ & $\begin{array}{c}\mathrm{DR} 2 \\
\left(\mathrm{~kg} / \mathrm{m}^{2} \cdot \min ^{0.5}\right)\end{array}$ & DI & $\mu$ ETICS & $\begin{array}{l}\mu \text { Thermal } \\
\text { Insulation }\end{array}$ & $\begin{array}{c}\text { Sd } \\
\text { finishing } \\
(\mathrm{m})\end{array}$ \\
\hline 1 & 0.10 & 0.027 & 0.000053 & 0.0027711 & 1.05 & 65.75 & & 1.12 \\
\hline 2 & 0.06 & 0.019 & 0.000050 & 0.0025406 & 1.05 & 65.22 & 42.45 & 1.15 \\
\hline 3 & 0.12 & 0.034 & 0.000113 & 0.0051086 & 1.02 & 44.27 & & 0.29 \\
\hline 4 & 0.92 & 0.193 & 0.000287 & 0.0154256 & 1.02 & 16.28 & & 0.54 \\
\hline 5 & 0.96 & 0.184 & 0.000252 & 0.0127771 & 1.01 & 16.78 & 8.86 & 0.54 \\
\hline 6 & 0.67 & 0.115 & 0.000283 & 0.0141846 & 0.98 & 32.63 & & - \\
\hline 7 & 0.77 & 0.172 & 0.000403 & 0.019722 & 0.94 & 42.20 & 35.81 & 0.58 \\
\hline 8 & 0.64 & 0.160 & 0.000280 & 0.0146646 & 0.98 & 6.73 & 1.90 & 0.31 \\
\hline 9 & 0.13 & 0.034 & 0.000110 & 0.0051607 & 1.03 & 12.06 & & - \\
\hline 10 & 0.23 & 0.081 & 0.000158 & 0.0079991 & 1.00 & 25.49 & 14.0 & 0.54 \\
\hline 11 & 0.15 & 0.049 & 0.000086 & 0.0043290 & 1.00 & 48.94 & 39.83 & 0.59 \\
\hline 12 & 0.42 & 0.151 & 0.000186 & 0.0099738 & 0.98 & 24.43 & 2.74 & 0.99 \\
\hline
\end{tabular}

When comparing the different systems, it can be noted that ETICS 1 and 3 have similar chroma, even if system 1 is closer to an ideal white (lower $\mathrm{C}^{*}$ ). On the other hand, system 2 have higher $\mathrm{L}^{*}$ and lower $\mathrm{C}^{*}$, being thus slightly brighter and more whitish than systems 1 and 3 . Those systems are the only ones with $-a^{*}$ values (green component).
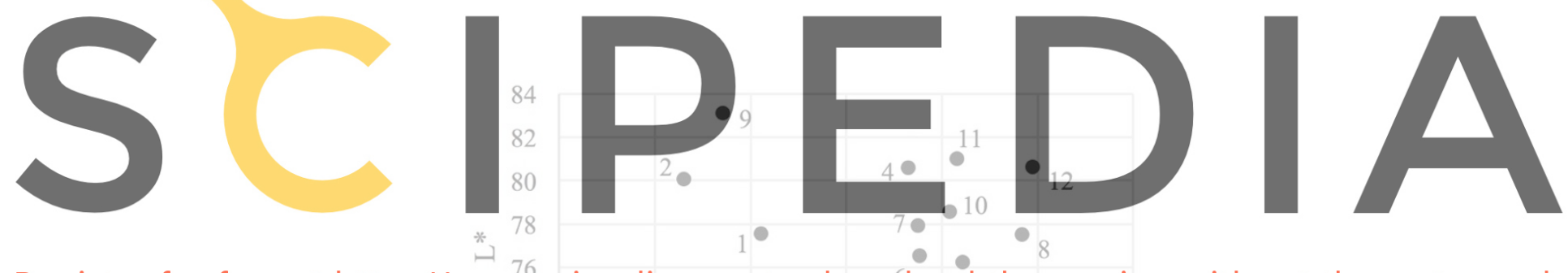

Register for free at https//www.scipedia.com to downloads the version without the watermark

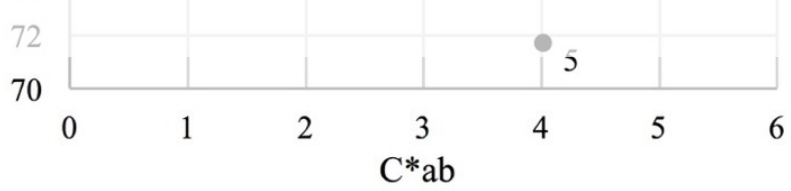

Figure 2. Comparison of the CieLAB values of the different ETICS.

When comparing systems 4 and 5, from the same producers and with the same thermal insulation (ICB), it can be noted a difference in $\mathrm{L}^{*}$ and $\mathrm{C}^{*}$, attributed to the difference in their finishing coating (lime-based and acrylic-based, respectively). Systems 6 to 8, although with different compositions, have similar chromatic coordinates. ETICS 10 to 12 (from the same producers, and with the same acrylic-based finishing coat) have similar colour, although system 10 has lower chroma, which might be related to the use of ICB as thermal insulation. On the other hand, system 9 (finished with a silicate- based coating), has even higher $\mathrm{L}^{*}$ and lower $\mathrm{C}^{*}$, being thus more close to an ideal white colour.

When considering brightness, it can be noted that those values are in agreement with colour values. In fact, systems 1 and 2 have similar brightness, whereas ETICS 3 (with co-polymeric 
acrylic finishing coat) has significantly lower values, when compared to 1 and 2 (both with $100 \%$ acrylic- based finishing coat). Systems 6 to 8 have similar GU values, whereas ETICS 5 (which differs for its ICB thermal insulation, when compared to systems 6 to 8 ) have lower values. Conversely, system 4 , finished with a (aerial and hydraulic) lime-based mortar, has brightness value which doubles that of system 5. Ultimately, systems 10 to 13 have similar brightness values, however, system 10 slightly differs from these systems, possibly due to its ICB thermal insulation. In agreement with colour values (Figure 2), system 9, is the only system with a silicate-based finishing coat, that has a considerably higher values when compared to systems 10 to 12 (all with acrylic-based finishing).

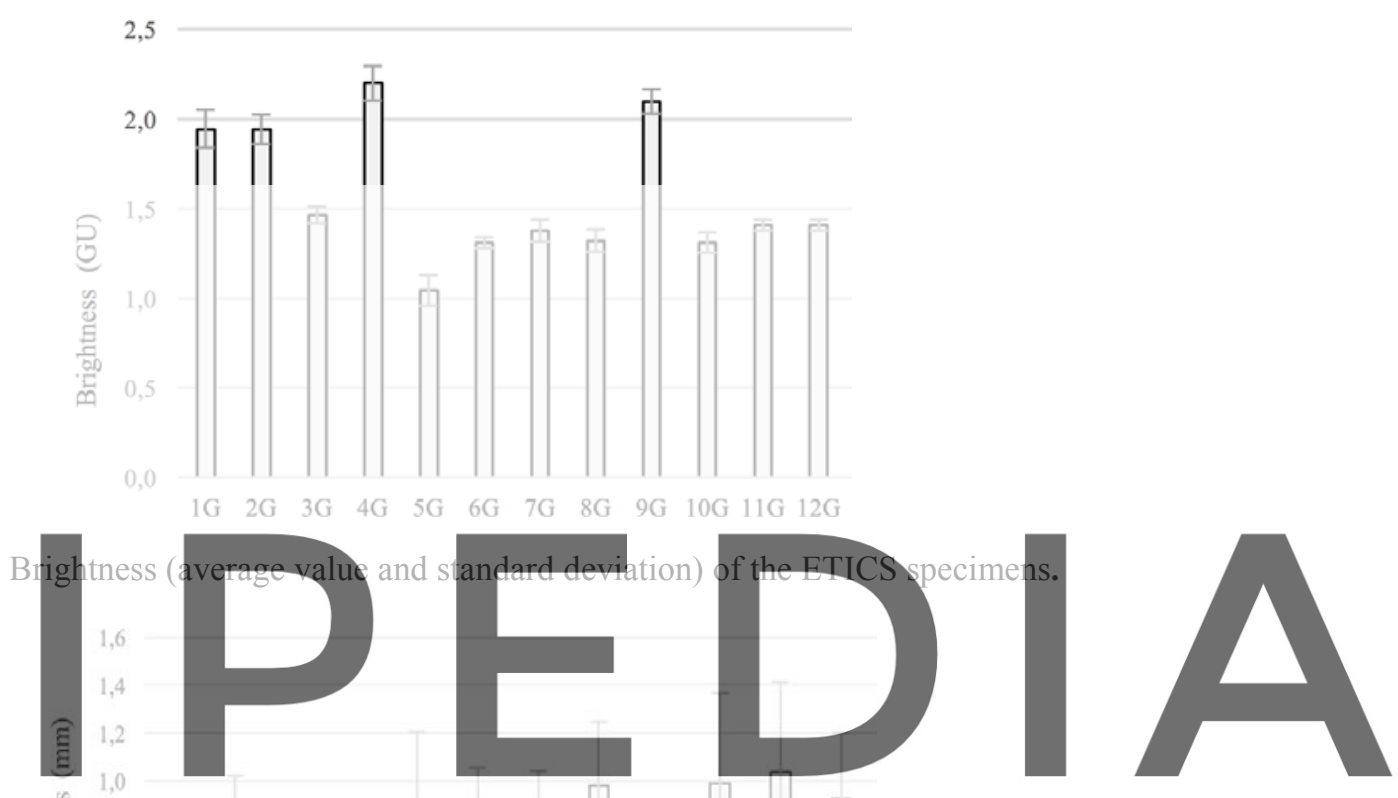

Register for free at https//wivw.scipedia.com to download the version without the watermark
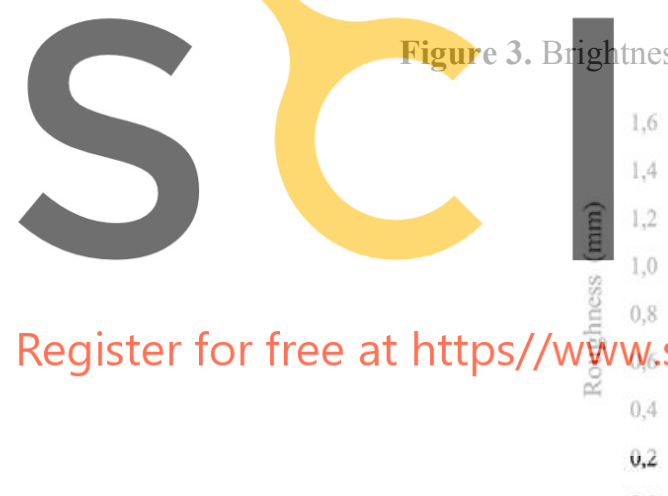

0,2
0,0

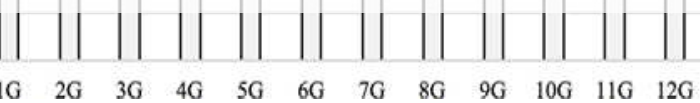

Figure 4. Surface roughness (average value and standard deviation) of the ETICS specimens.

\subsection{Surface Roughness}

Results show that systems 1, 4 and 9 (one for each producer) present the lower roughness values $(467 \mu \mathrm{m}$ to $580 \mu \mathrm{m})$ (Figure 4 ). When comparing systems 1 to 3 , from the same producers, it can be noted that systems 2 and 3 have higher values, when compared to ETICS 1 , due to the use of a coarser (co- polymeric-based) finishing coat. Systems 5 to 7, although with different compositions, have similar roughness values, whereas system 8 (with MW thermal insulation) have slightly higher (15\%) values. The significant lower values of ETICS 4 can be attributed to the use of a thin lime-based layer as finishing coat, when compared to the systems 5 to $8(784 \mu \mathrm{m}$ to $978 \mu \mathrm{m})$, which present coarser mineral aggregates in their finishing coat. Ultimately, systems 10 to 12, which have the same acrylic- based finishing coat, have similar roughness $(874 \mu \mathrm{m}$ to $1035 \mu \mathrm{m})$, with slightly lower values in system 12 . On the 
other hand, ETICS 9, which is finished with a silicate-based coat, has remarkably lower surface roughness, comparable to that of systems 1 and 4.

When comparing the moisture transport properties and roughness of the 3 different producers, it is worth highlighting that systems 1 to 3 , with relatively low roughness $(0,575$ $\mu \mathrm{m} 0,761 \mu \mathrm{m})$, have also low water capillary absorption. Conversely, ETICS 5 to 8 have slightly higher roughness $(0,704 \mu \mathrm{m}$ to $0,978 \mu \mathrm{m})$ and significantly higher water capillary absorption. A trend similar to the latter systems is observed with ETICS 10 and 12. Interestingly Systems 4 show both low roughness and capillary absorption, whereas systems 11 have low roughness and considerably high water absorption (and drying rate). This can be explained again by the composition of these systems (lime-based finishing for ETICS 4, silicate-based coating for ETICS 9).

\section{Conclusions}

The aim of this paper is the evaluation of the moisture transport properties and surface properties of commercially available external thermal insulation composite systems (ETICS).

Results showed that all systems respected the hygric requirements of ETAG for the technical approval of ETICS, i.e. all have capillary absorption lower than $1 \mathrm{~kg} / \mathrm{m}^{2}$ at $1 \mathrm{~h}$ and a suitable water vapour permeability (diffusion-equivalent air-layer thickness $<2 \mathrm{~m}$ ). It was observed that, generally, systems that absorb more water are those that have higher dry rates and higher water vapour permeability (as in the case of systems 4 to 8, from the same

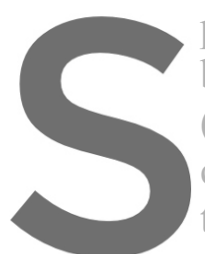
producer).Conversely, behaviour. Furthermore, (system 9) has lowe compared to other systert thermal insulation on systems 11 (EPS) and 12 (MW)
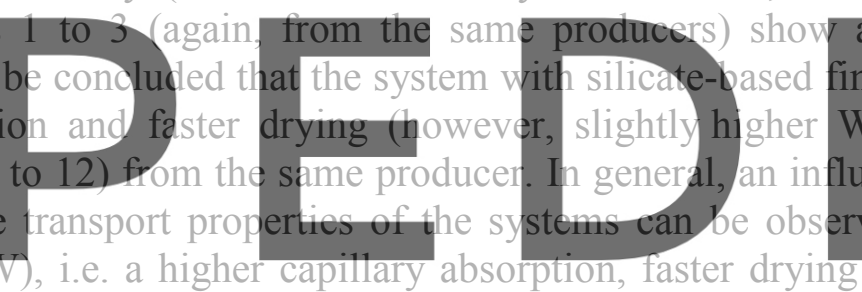

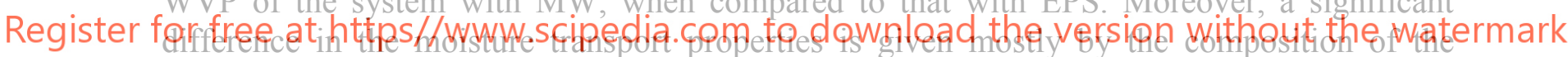

finishing render (base and finishing coats), rather than the surface properties (e.g. roughness).

When observing results of the optical surface tests, it can be seen that the systems with acrylate- based finishing coat are generally less whitish and less bright, when compared to systems finished with silicate-based (ETICS 9) or lime-based (ETICS 4) systems.

Ultimately, it was observed that systems 1, 4 and 9 (one of each producer), the ones with the highest colour and brightness values, have also the lowest roughness values. The higher values of the other systems are attributed to the addition of mineral loads (aggregate) in the finishing coat.

It should be noted that all systems were tested in ideal conditions (no exposure to external weathering). For this reason, further tests are ongoing to assess the moisture transport properties and surface properties of ETICS before and after natural and artificial aging.

\section{Acknowledgements}

The authors acknowledge the Portuguese Foundation for Science and Technology (FCT) for the financial support of the research project PTDC/ECI-EGC/30681/2017 (WGB_Shield - Shielding building' facades on cities revitalization. Triple resistance for water, graffiti and biocolonization of external thermal insulation systems). 


\section{ORCID}

Giovanni Borsoi: https://orcid.org/0000-0002-2194-4620

João Luís Parracha: https://orcid.org/0000-0001-6214-3400

Inês Flores-Colen: https://orcid.org/0000-0003-4038-6748

Amélia Dionísio: https://orcid.org/0000-0001-8016-4029

Maria do Rosário Veiga: https://orcid.org/0000-0002-7135-8603

\section{References}

ASTM D6578-00, 2000. Standard Practice for Determination of Graffiti Resistance. ASTM International, Pennsylvania, USA.

Barreira, E. and P. de Freitas, V. (2013). Experimental study of the hygrothermal behaviour of External Thermal Insulation Composite Systems (ETICS). Building and Environment, 63, 31-39.

Energy Performance of Building Directive (EPBD) (2010). Directive 2010-31-EU of the European Parliament and of the Council, Official Journal of the European.

EN 16322 (2013). Conservation of Cultural Heritage - Test methods - Determination of drying properties. European Committee for Standardization, Brussels, Belgium.

EOTA (2013). Guideline for European Technical Approval of External Thermal Insulation Composite Systems with Rendering. ETAG 004, Brussels.

Pasker, R. (2017). The European ETICS market - Do ETICS sufficiently contribute to meet political objectives?, in 4th European ETICS Forum, Warsaw, Poland.

Schiavoni, S., D'Alessandro, F., Bianchi, F. and Asdrubali, F. (2016). Insulation materials for the building sector: A review and comparative analysis, Renewable and Sustainable Energy Reviews, 62, 988-1011.
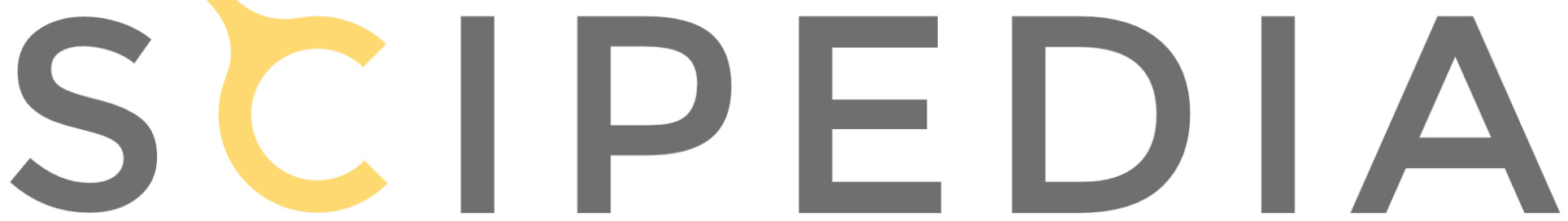